\title{
Think Mathematic, Gain Orthodontic. Innovative modification of Tonn formula to calculate mesiodistal width of missing lower incisors
}

\author{
Dr. Abhishek Bansal, Dr. Thomas John, Dr. Vaki chinde, Dr. Laique Sami, \\ Dr. Adnan Ahmed, Dr. Arihant Jain, Dr. Asiya Fatima
}

\begin{abstract}
The incidence of congenital absence of lower incisors though is statistically low but still is area of concern for orthodontists. Also, chances of losing lower anteriors due to periodontal pathology are high due to its location, which is a concern in adult orthodontics. For the achievement of an ideal occlusion and a good intercuspation, we need to identify the interarch tooth size discrepancy calculated using the individual tooth size. Thereby, in cases with missing lower incisors, considering the tooth size of the missing tooth is questionable. Therefore, we have proposed an innovative mathematical modification of Tonn formula for the prediction of the mesiodistal width of the missing lower anterior tooth. The use of this method in our department is a testimony of its usefulness.
\end{abstract}

Keywords: Missing tooth, Tonn formula, mixed dentition analysis, Prediction, incisors, periodontal pathology.

The incidence of congenital absence of lower incisors though is statistically low but still is area of concern for orthodontists. ${ }^{1}$ Also, chances of losing lower anteriors due to periodontal pathology is high due to its location, which is an area of concern in the field of orthodontics. Orthodontic treatment objectives mainly includes fulfilment of three main goals: Functional efficiency, Structural balance \& Esthetic harmony ${ }^{2,3}$ but it also includes aligning the teeth into arch. To achieve these goals, we must have a proper inter-digitation of opposing teeth of both the arches, which is only possible if we know the total tooth material in an arch and their interrelationship, so that in case of any discrepancy it could be matched to achieve a good occlusion.

Though there are many model analyses into existence, but Bolton's analysis ${ }^{4}$ for the prediction of interarch tooth size discrepancy has stood to the test of time. Bolton's discrepancy analysis is one of the diagnostic tools which dictates the extraction plans and the replacement plans as indicated in an orthodontic practice. ${ }^{5}$

There are a few mixed dentition model analysis which predicts the tooth size of canines and premolars based on the mesiodistal width of incisors. A few of the most commonly used analysis are Moyer's mixed dentition analysis ${ }^{6}$, Tanaka Johnson mixed dentition analysis ${ }^{7}$, Huckaba's analysis ${ }^{8}$ etc. Along with these, Tonn formula ${ }^{9}$ is a god tool to assess the sum of incisors using the sum of lower incisors. But till date, no literature is available to calculate lower incisor tooth width using upper incisors. Thereby, we have modified the Tonn formula to assess the lower incisor tooth width using that of the uppers.

Thinking logically, If $1+1=2,1.5+0.5=2$, and $2 \times 2 / 2=2$, why not $2-1=1,2-1.5=0.5$, and 2 x $2 / 4$ = 1 . Confused?????

Simple, if we could predict the mesiodistal width of Upper incisors taking the mesiodistal width of lower incisors using Tonn formula, why can't we go the other way round? In cases of impacted \& missing lower anteriors, we could use the width of upper incisors for calculating the mesio-distal width of lower incisors, which could be used for performing Bolton's analysis.

Tonn Formula :

Sum of upper incisors $=($ Sum of lower incisors $x$ 4/3 $)+0.5$

Modified Tonn Formula (We named it as Abhi's Formula):

Sum of lower incisors $=($ Sum of upper incisors -0.5$) \times 3$

4

Here is a case presented as an example to explain the logic and the applicability of the Abhi's Formula for predicting the width of impacted/ missing lower incisor teeth.

A 15 year old male patient having a class I malocclusion with missing lower lateral incisors (32 and 42) and an impacted lower right canine (43). Due to missing teeth, Bolton's analysis was not applicable. But as the case demanded tooth size discrepancy prediction, we tried to go the other way round to estimate the tooth material values. The measurement of the teeth in each quadrants are as follows: 


\begin{tabular}{|l|l|l|l|l|l|l|l|l|l|l|l|l|}
\hline $\begin{array}{l}\text { Tooth number } \\
\text { (FDI System) }\end{array}$ & 16 & 15 & 14 & 13 & 12 & 11 & 21 & 22 & 23 & 24 & 25 & 26 \\
\hline $\begin{array}{l}\text { Tooth size } \\
(\mathrm{mm})\end{array}$ & 11 & 7.5 & 8.0 & 8.5 & 8.5 & 11 & 11 & 8.5 & 8.5 & 8.0 & 7.5 & 11 \\
\hline $\begin{array}{l}\text { Tooth size } \\
(\mathrm{mm})\end{array}$ & 12.5 & 8.0 & 8.5 & $\mathbf{U E} *$ & - & 7.0 & 7.0 & - & 8.0 & 8.5 & 8.0 & 12.5 \\
\hline $\begin{array}{l}\text { Tooth number } \\
\text { (FDI System) }\end{array}$ & 46 & 45 & 44 & 43 & 42 & 41 & 31 & 32 & 33 & 34 & 35 & 36 \\
\hline
\end{tabular}

Note: $\mathbf{U E}^{*}$ = Unerupted tooth.

The width of unerupted right canine can be considered similar to that of left canine of same arch, or else be calculated using Huckaba's analysis. following:

For the prediction of mesiodistal width of missing lower lateral incisors, we applied the formula as

\section{Modified Tonn Formula (Abhi's Formula):}

$$
\text { Sum of lower incisors }=(\text { Sum of upper incisors }-0.5) \times 3
$$

\section{4}

Sum of lower incisors $=(39-0.5) \times 3 / 4$

Therefore value obtained by calculation $=28.8 \mathrm{~mm}$

Thus using this formula we obtained following values:

\begin{tabular}{|l|l|l|l|l|}
\hline $\begin{array}{l}\text { Width of Upper } \\
\text { incisors }\end{array}$ & $\begin{array}{l}\text { Sum of lower } \\
\text { incisors width }(\mathrm{X})\end{array}$ & $\begin{array}{l}\text { Sum of lower central } \\
\text { incisors }(\mathrm{Y})\end{array}$ & $\begin{array}{l}\text { Estimated Lateral } \\
\text { incisors width Z = (X- } \\
\text { Y) }\end{array}$ & $\begin{array}{l}\text { Width of single lateral } \\
\text { incisor (Z/2) }\end{array}$ \\
\hline $39 \mathrm{~mm}$ & $28.8 \mathrm{~mm}$ & $14 \mathrm{~mm}$ & $14.8 \mathrm{~mm}$ & $7.4 \mathrm{~mm}$ \\
\hline
\end{tabular}

These values match to that of the anatomic values given in various authorized dental anatomy text books. Therefore, this method is correct and can be used to predict the mesiodistal width of missing lower incisors.

Indications:

- In cases with missing tooth

- Cases with impacted tooth.

\section{Advantages:}

In cases with gross crowding along with unerupted teeth.

- It helps as a guiding path in the estimation of inter arch discrepancy.

- Has a futuristic view for the malocclusion correction.

Disadvantages:

- In case of replacement, gives us the estimated size of tooth to be replaced.

- Though approximately correct, but exact values are not always necessarily calculated.

\section{Conclusion:}

The use of this simple mathematical formula (Abhi's Formula) can be used as a valuable clinical aid in predicting an approximate value for the missing tooth, placing itself amongst the other well-known tooth material prediction methods.

\section{References:}

[1]. Adrian Becker. The orthodontic treatment of impacted teeth. 1998, Martin Dunitz Ltd. London.

[2]. William R. Proffit, H. Fields, \& D.Sarver. Contemporary Orthodontics: $4^{\text {th }}$ Edition; 2007, Mosby Elsevier Publications.

[3]. T. M. Graber, Robert. L. Vanarsdall, Katherine W.L. Orthodonitcs: Current principles and techniques; $4^{\text {th }}$ Edition, Elsevier Mosby Publications, 2000

[4]. Wayne A. Bolton. Disharmony in tooth size and its relation to the analysis and treatment of malocclusion. Am. J Orthod Dentofacial Orthop July 1958; 28(3):113-130.

[5]. Marianne Heusdens, Luc Dermaut, Ronald Verbeeck. The effect of tooth size discrepancy on occlusion: An experimental study. Am. J Orthod Dentofacial Orthop 2000;117:184-91

[6]. Robert E. Moyers. Handbook of orthodontics, $4^{\text {th }}$ edition. 1988. Year book medical publishers, Inc.

[7]. Tanaka MM, Johnston LE. The prediction of the size of unerupted canines and premolars in a contemporary orthodontic population. J Am Dent Assoc. 1974; 88:798-801.

[8]. Huckaba GW. Arch size analysis and tooth size prediction. Dent Clin North Am 1964; 11:431-40.

[9]. Thomas Rakosi, Irmtrud Jonas, Thomas m. Graber. Color atlas of Dental medicine, $1^{\text {st }}$ edition. 1993. Thieme medical publishers Inc. New York. 